\title{
LOS JUECES DIPUTADOS Y LOS DISTRITOS JUDICIALES BORBÓNICOS EN CHILE (1786-1818)*
}

\author{
DEPUTY JUDGES AND BOURBON JUDICIAL DISTRICTS IN CHILE \\ (1786-1818)
}

\section{Dra. LUCRECIA ENRÍQUEZ ${ }^{* *}$}

\begin{abstract}
RESUMEN: Se analiza la delimitación de los distritos judiciales rurales en las subdelegaciones chilenas y los jueces diputados de subdelegado definiéndolo como la figura a través de la cual llegaba el estado monárquico a toda la gobernación por sus facultades de gobernar un distrito o diputación y celar sobre los delitos vinculados a vagabundos, ociosos, ladrones y malentretenidos. El estudio se inicia con la decisión de la Junta Superior de Real Hacienda de instituir este tipo de juez rural en el momento de la implantación del régimen de intendencias en 1786 y su continuidad durante el proceso de independencia.
\end{abstract}

Palabras clave: Juez diputado, Reformas Borbónicas, Subdelegación, Justicia, Independencia

ABSTRACT: The delimitation of the rural judicial districts is analyzed in Chilean sub-delegations, and the deputy judges of Subdelegado defining it as the figure through which came the monarchical state to the entire government of Chile for his faculties to govern a district or deputy and celar on crimes linked to lawbreakers like vagabundos, ociosos, ladrones and malentretenidos. The study begins with the decision of the Superior Board of the Royal Treasury to institute this kind of rural judge at the time of implantation intendant regime in 1786 and its continuity during the independence process.

Keywords: Deputy Judge, Bourbon Reforms, Subdelegations, Justice, Independence

\section{INTRODUCCIÓN}

La historiografía sobre las reformas borbónicas ha ido paulatinamente oscilando desde un estudio centrado en una monarquía reformista que implantó las intendencias ${ }^{1}$ hacia otro basado en la recepción de las reformas en territorios concretos ${ }^{2}$, aunque la mirada se ha puesto en las grandes divisiones administrativas como virreinatos o capitanías generales ${ }^{3}$.

\footnotetext{
Este artículo forma parte del proyecto Fondecyt No 1141115 "Intendencias y subdelegaciones en Chile (1786-1833)", del que la autora es investigadora principal. Agradezco los comentarios a este artículo del Dr. Rafael Diego Fernández Sotelo y del Dr. Darío Barriera.

** Académica del Instituto de Historia de la Pontificia Universidad Católica de Chile, Doctora en Historia por la Pontificia Universidad Católica de Chile (2004) y Doctora en Historia Moderna y Contemporánea por la Universidad de Bordeaux 3, Michel de Montaigne (2004). Dirección postal: Av. Vicuña Mackenna 4860, Macul, Santiago, Chile. Dirección electrónica: lenriqua@uc.cl;

1 Navarro (1959); Morazzani (1966); Navarro (1995); Lynch (1996); Navarro et al. (2005); Navarro (2009).

2 Entre otros véase Ortelli (2006); Lorandi (2008); Altable (2013); Reyes et al. (2013).

3 Pietschmann (1996); Lynh (2001).
} 
Pero poco conocemos sobre cómo funcionaban las intendencias y las subdelegaciones. Recientemente, la Red de Estudios del Régimen de Subdelegaciones de la América Borbónica (RERSAB), coordinada desde El Colegio de Michoacán, ha comenzado a llamar la atención sobre la importancia de los intendentes y subdelegados, e integrar en nuestros análisis territoriales a estos funcionarios borbónicos y su jurisdicción. ${ }^{4}$ Este artículo se inscribe dentro de las líneas maestras de la RERSAB, analizando los jueces diputados en las subdelegaciones chilenas, tema muy poco abordado. En este trabajo nos detendremos fundamentalmente en el juez diputado y su institución a partir de la implantación del régimen de intendencias. Sin duda es la figura más olvidada de la historiografía chilena dedicada al último tercio del siglo XVIII, aunque aparece actuando por doquier en todos los trabajos relativos al mundo rural. Su novedad, sus facultades judiciales y administrativas, su origen social, su ausencia de la historiografía y su presencia en los archivos de la Capitanía General y la Real Audiencia, nos parecen razones de peso para que los analicemos. Nuestra hipótesis es que el juez diputado de subdelegado fue la figura clave del proyecto borbónico de población, toma efectiva de posesión y control del territorio, a través del cual llegó el estado monárquico a todos los rincones de la gobernación. Con este fin recibieron las facultades directamente del intendente de gobernar un distrito o diputación y celar sobre los delitos vinculados a vagabundos, ociosos, ladrones y malentretenidos. Describiremos la estructura judicial rural previa a la implantación del régimen de intendencias para situar en ella los jueces diputados. Utilizamos para ello las fuentes disponibles: su institución, facultades, nombramientos y diagnóstico de sus actividades por las autoridades. No se han conservado ninguna causa sustanciada por los jueces diputados ni los archivos de los subdelegados en el periodo estudiado.

Razones de espacio y la opción por centrar el trabajo en los jueces diputados, nos impiden describir en cada momento a fondo el funcionamiento de la justicia, lo que requiere un trabajo de mayor envergadura, y detenernos en otro tipo de jueces de los fueros eclesiástico, minero, militar y comercial.

\section{EsTAdo de LA CUESTIÓN}

Desde hace pocos años se han desarrollado en diferentes países "redes de estudio de la justicia”, tanto seglar como eclesiástica. Sin duda llenan un vacío historiográfico producido en los últimos decenios por corrientes que han acentuado lo económico o lo político como motor principal del acontecer histórico. Los temas judiciales, en cambio, fueron en el pasado objeto casi exclusivo de estudio por parte de los historiadores de la historia del derecho. Los nuevos grupos que estudian "la justicia" no provienen de ese ámbito, son historiadores de formación universitaria que se acercan a las fuentes judiciales con nuevas miradas desde la historia social, política, cultural.

Estudiar los distritos judiciales de las subdelegaciones implica adentrarnos en el tema de la justicia en el mundo rural, tema que interesó a los historiadores americanos dedicados a la época colonial a partir de 1960, desde la óptica del sujeto juzgado por su homogeneidad y aparición simultánea en la América española. La atención efectivamente

\footnotetext{
DiEGo et al. (2014).
} 
fue puesta en el vagabundo, ocioso, ladrón, malentretenido, el que fue estudiado en múltiples formas. Norman Martin lo analizó como sujeto merecedor de asistencia social ${ }^{5}$. Mario Góngora acentuó el carácter delictivo del vagabundo ${ }^{6}$. Carlos Mayo estudió el vagabundaje como fenómeno del mundo de la frontera y en relación a la mano de obra rural ${ }^{7}$. En la misma línea se sitúan los trabajos de Miguel Izard para Venezuela ${ }^{8}$. En Chile, Alejandra Araya analizó a los vagos y ociosos como sujetos existentes solo en el discurso ilustrado? Jaime Valenzuela consideró el fenómeno en el valle central de Chile acentuando la asimilación de la época entre vago, malentretenido y bandido rural ${ }^{10}$. José Bengoa da cuenta de la marginalidad social en la que vivían los vagabundos ${ }^{11}$. En España, el vagabundaje ha sido estudiado como fenómeno de pobreza ${ }^{12}$. El vínculo entre peonaje obligatorio y vagabundaje fue destacado por Gabriela Martínez ${ }^{13}$. Un artículo reciente de María Elena Barral, Gladys Perri, Raúl Fradkin y Fabián Alonso reconstruye la construcción del vago como figura delictiva ${ }^{14}$. En otro artículo, Barral, Perri y Fradkin, se centran en las concepciones jurídicas y prácticas judiciales en la campaña bonaerense ${ }^{15}$.

De diferentes maneras, las fuentes en Iberoamérica se refieren a este sujeto que es a la vez un malentretenido, vago, ocioso, bandido, marginal, delincuente, categorías que han sido tomadas por los historiadores como puntos de análisis, y que dieron origen a que el estado construyera un sistema de control sobre esta población. Durante el siglo XVIII diversos funcionarios reales recibieron la comisión de prender a estos sujetos, o las causas contra ellos fueron incluidas en su jurisdicción.

Paulatinamente el interés por el mundo rural ha puesto la lente no en sujeto juzgado sino en el juez que lo juzga. Un desarrollo importante y fecundo de esta corriente ha tenido lugar en la historiografía argentina. El impacto que sobre el antiguo virreinato tuvieron las reformas borbónicas, el desarrollo que implicaron y la cantidad de huellas documentales que han dejado a nivel local, ha dado origen a un profundo conocimiento del período en sí mismo, su continuidad y su transformación paulatina a lo largo del siglo XIX. Un artículo pionero de Darío Barriera y Gabriela dalla Corte ${ }^{16}$ mostró la riqueza de volver hacia los archivos judiciales y escuchar las voces de quienes no habían sido suficientemente oídos. Por su parte Gabriela Tío Vallejo ${ }^{17}$ analizó cómo confluyeron en la necesidad de estudiar la justicia, diferentes corrientes como la historia agraria, los estudios sobre el colapso del régimen

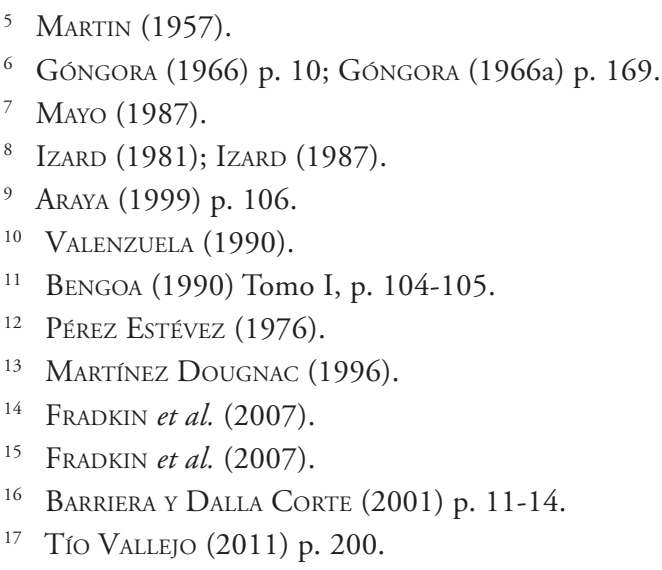


colonial y los relativos a la etapa de las autonomías provinciales. La historiografía argentina nos ofrece, por tanto, un corpus de estudio interesante, nuevo y a la vez reciente, sobre la red judicial en el mundo urbano y rural desde su estructuración en el último cuarto del siglo XVIII, el impacto que sobre ella produjo la independencia y su nueva estructura a partir de 1820. Una serie de historiadores de las actuales provincias de Mendoza, Tucumán, Santa Fe, Córdoba, Buenos Aires, han rescatado de los archivos provinciales numerosas fuentes que permitieron definir especifidades judiciales vinculadas a desarrollos políticos y sociales locales. De esta manera han aportado hipótesis de trabajo que rescatan la aplicación a escala local del impacto de las reformas borbónicas, por ejemplo, o el proceso a través del cual cada provincia puso en pie una red judicial después de la independencia.

Un punto en común de toda esta historiografía es detenerse en el estudio de la justicia rural analizando en profundidad una de sus fuentes de origen, el cabildo. Centran el estudio en los alcaldes de la hermandad, el alcalde provincial de la hermandad y en la paulatina judicialización del campo a través de jueces comisionados, cuadrilleros, pedáneos. Gabriela Tío Vallejo ${ }^{18}$, por ejemplo, analizó cómo en Tucumán el poder del cabildo se fortaleció reformando la administración de la justicia. A los alcaldes de la Santa Hermandad, se sumaron los jueces pedáneos o territoriales establecidos en el campo a partir de 1770, cuyos nombramientos se originaron en peticiones de vecinos. Los nombraba el cabildo, eran comisionados y sin jurisdicción fija. En Santa Fe el tema fue estudiado por Darío Barriera vinculando también en el período de las reformas borbónicas las "formas de administración de la justicia rural y los procesos de organización territorial" ${ }^{19}$. El autor afirma que la iniciativa de judicializar el campo también habría partido del cabildo, complementando las tareas de los alcaldes de la hermandad y provinciales de la hermandad, con el nombramiento de jueces pedáneos y comisionados a partir de 1767.

Raúl Fradkin sostiene que también en Buenos Aires a partir de 1777 el cabildo designó alcaldes rurales, acentuándose el control urbano sobre el mundo rural. En 1784, el Gobernador Intendente autorizó al cabildo a nombrar cuantos alcaldes considerara necesarios, llegándose en 1810 a 19 jurisdicciones dependientes del cabildo de Buenos Aires ${ }^{20}$. Juan Carlos Garavaglia ${ }^{21}$ puntualiza que el control social de la campaña se hizo a través de la multiplicación de los alcaldes de la hermandad, llegando a ser 25 en 1815 ya que ejercían una función judicial y de policía. Para el autor, la justicia rural en la campaña de Buenos Aires dependió de los dos cabildos existentes, Luján y Buenos Aires. Incluso, a partir de la instalación en 1785 de la Audiencia en la capital virreinal, fueron los Alcaldes de la Hermandad quienes vincularon el mundo rural con la Real Audiencia y el virrey.

El caso mendocino, estudiado por Eugenia Molina, se enmarca dentro de la misma línea de destacar la particularidad local en el desarrollo de la red judicial. Para la autora la desaparición del corregidor en 1785 fortaleció la autoridad del cabildo sobre el territorio

\footnotetext{
18 Tío Vallejo (1998).

19 Barriera (2012) p. 2.

20 Fradkin (2009) p. 86.

21 Garavaglia (1999) p. 149.
} 
que controlaba de diversas formas, entre ellas destaca la instalación de jueces, a los que la autora denomina como menores ${ }^{22}$. Además, el crecimiento de la ciudad y de la población rural llevó a la necesidad de nombrar alcaldes de barrio en un área inmediata a la ciudad y en parajes alejados, lo que implicó que no se reprodujera el esquema urbano/rural de otras ciudades, que reservaban las áreas rurales exclusivamente para los alcaldes de la hermandad. Convivieron y se diferenciaron de los jueces comisionados, nombrados por el cabildo, corregidor, intendente, gobernador o virrey, y actuaron en causas vinculadas a la provisión de agua.

Rescatamos de esta corriente los aportes hechos al tema en relación el estudio de la red de justicia en su propio contexto local, a las autoridades que la estructuraron, a los diagnósticos que le dieron origen. El cabildo aparece como la institución fundamental de la que emanó la justicia rural.

En Chile nos encontramos con un panorama judicial diferente que el descrito por la historiografía argentina para el mundo rural y bastante más complejo. La red de justicia no estaba monopolizada por los cabildos. En la campaña encontramos diferentes tipos de jueces nombrados por todas las autoridades con jurisdicción. De hecho, nuestro acercamiento al tema de las diferentes justicias nace del interés por conocer diputaciones judiciales de subdelegado, , su funcionamiento y, en la medida de lo posible, el origen social de los nuevos jueces diputados. La asociación que aparece por doquier en la documentación consultada es la del juez hacendado o juez mayordomo de hacienda.

La primera gran diferencia con el caso del virreinato del Río de la Plata durante el mismo período, es que en Chile encontramos en el mundo rural además de los jueces nombrados por los cabildos, alcaldes de la Hermandad y juez de aguas, los nombrados por el Presidente de la Audiencia, los llamados jueces comisionados y, a partir de la implantación del régimen de intendencias, los jueces diputados. El subdelegado era un Justicia Mayor y, en las subdelegaciones con asientos mineros, era además Alcalde mayor de Minas y contaba con sus tenientes de alcalde.

En Chile, la fuente de origen de la judicialización rural no fueron solo los cabildos, sino también los corregidores, los intendentes, subdelegados y los Presidentes de la Audiencia. Los cabildos chilenos estaban suspendidos en las villas de Copiapó, San Felipe, Quillota, Melipilla, San Fernando y Chillán y no fueron establecidos en las poblaciones erigidas a partir de 1752 (Illapel, Petorca, La Ligua, Casablanca, Alhué, Rere, Hualqui, entro otras). Comenzaron a ser repuestos parcialmente a partir de $1780^{23}$, por lo que una importante zona de Chile no contó con este cuerpo capitular. La autoridad de los corregidores chilenos y su peso político a nivel provincial no tuvo un contrapeso como el que podía ofrecer un cabildo controlado por una elite local fuerte ${ }^{24}$. La revisión de las actas de los cabildos que han llegado hasta nosotros y de los informes de las elecciones capitulares enviadas para su confirmación al Presidente, nos muestra, como en el caso del cabildo de Talca, que se

\footnotetext{
22 Molina (2011) p. 183.

23 Cobos y Lorenzo (1985) p. 76.

24 Cobos y Lorenzo (1985) p. 69; Lorenzo (1999) pp. 131-139.
} 
nombraba para la campaña un Alcalde de la Hermandad por doctrina, y un juez de aguas ${ }^{25}$. Existía además el juez de abastos (que reemplazó a los fieles ejecutores) que era un regidor, y un Alcalde Mayor Provincial de la Santa Hermandad, más los alcaldes de primero y segundo voto.

La justicia en las intendencias y subdelegaciones chilenas es un tema no estudiado, ni siquiera en una descripción general del régimen de justicia ${ }^{26}$. Bernardino Bravo Lira inserta las reformas a las judicaturas indianas en una descripción general de las reformas borbónicas en Hispanoamérica ${ }^{27}$, aunque sin considerar las funciones judiciales de intendentes, subdelegados y jueces diputados. María Teresa Cobos en un artículo pionero, sacó a la luz a los múltiples jueces que en el siglo XVIII actuaban en el mundo rural. La denominación de los mismos como "jueces de campo" unificó a un conjunto de jueces cuyas funciones, origen de facultades y temporalidad a veces se sucedieron o coexistieron, $\mathbf{y}$ cuyas funciones no fueron las mismas lo que, junto con la constante comparación entre ellos, creemos dificulta la comprensión de las judicaturas analizadas. Aunque la autora reconoce que el juez de campo como figura no existió en el siglo XVIII, definió y unificó estas judicaturas como "instituciones menores del derecho indiano" ${ }^{2}$. La denominación de "juez de campo' se ha traspasado a la historiografía desde la aparición del texto de María Teresa Cobos, y su aplicación no ayuda a entender la justicia en el mundo rural. Probablemente el origen de esta denominación sea otro. Los archivos de los jueces diputados están conservados en el Archivo Nacional de Chile, fondo Notarios, y guardan sus actuaciones como ministros de fe en el mundo rural. Esta función la tenían los tenientes de corregidor y, después de su abolición en 1786, fue conferida a los jueces diputados quienes heredaron los archivos de los tenientes con las actas notariales de sus distritos. En dicho repositorio recibieron estos archivos la clasificación de "juez de campo" lo que probablemente también contribuyó a denominar de esta manera a los jueces en su conjunto y acentuó la imagen de continuidad entre ellos.

Sergio Martínez Baeza en un trabajo sobre la fe pública en el Chile indiano, se detuvo en los ministros de fe y bajo este prisma nombró a los jueces diputados confundiéndolos con los tenientes de corregidores. De hecho, para este autor todos los jueces subalternos eran lugartenientes de corregidor con numerosas denominaciones:

"El referido lugarteniente del corregidor tuvo numerosas denominaciones, tales como teniente, teniente de justicia, juez diputado, juez subalterno, juez partidario, juez celador, teniente de campaña, etc. Eran escogidos y nombrados por el corregidor" ${ }^{29}$.

Si bien Martínez Baeza menciona la implantación del régimen de intendencias, desconoce que implicó cambios en la administración de la justicia distrital. Lo mismo ocurre con la explicación sobre la justicia colonial en el mundo rural en el siglo XVIII que hacen Claudia Arancibia Floody, José Tomás Cornejo Cancino, Carolina González Undurraga,

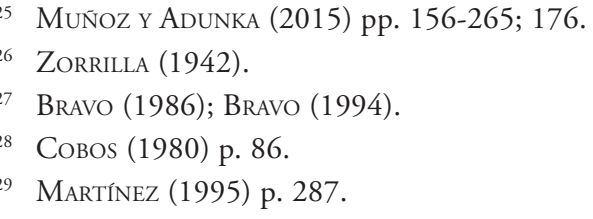


aplicando la misma categoría de juez de campo de Cobos: "La jurisdicción en zonas rurales la ejercían los alcaldes de la Santa Hermandad y los jueces de campo, diputados o comisionados" ${ }^{30}$, aunque estos últimos no juzgaban.

En este último texto, incluso, se explica el funcionamiento de la justicia colonial partiendo por cómo se iniciaba una causa judicial y quiénes conocían en ellas, llegando a establecerse una sucesión de posibles jueces competentes sobre una causa (los alcaldes ordinarios, corregidores, Real Audiencia, jueces comisionados, jueces diputados). Varias de estas justicias no fueron contemporáneas e incluso no administraban justicia.

Antonio Dougnac menciona a los jueces diputados al explicar los actos procesales orales en los juicios ordinarios penales, y describe de manera general cómo debían levantar el auto cabeza de proceso según las instrucciones del gobernador Tomás Álvarez de Acevedo ${ }^{31}$. María Eugenia Albornoz, por su parte, se ha centrado en los juicios por injurias analizando fundamentalmente en ellos los sujetos involucrados y los conflictos entre las partes, sin un enfoque directo de la figura del juez diputado ${ }^{32}$.

\section{Los jueces diputados en Chile}

El interés por estudiar la justicia en las subdelegaciones e intendencias es reciente. José Luis Alcauter lo ha hecho para México, dedicando un capítulo entero de su tesis doctoral al estudio de la administración de justicia en dichos distritos ${ }^{33}$. Su análisis parte por la real ordenanza de intendentes para la Nueva España, la supresión consiguiente de los corregidores, alcaldes mayores y sus tenientes de justicia. Estos jueces fueron reemplazados por los subdelegados y nuevos alcaldes ordinarios, sin que se contemplara la posibilidad de que tuvieran tenientes de justicia dado que al aumentar las jurisdicciones se creyó que no serían necesarios. Sin embargo, pronto los subdelegados comenzaron a nombrar tenientes de diferentes formas: directamente, vendiendo el cargo o por medio del pedido de una fianza a los tenientes, asociándose con los vecinos de algún paraje para definir quién sería teniente, o pidiendo el nombramiento al intendente, aunque este no tenía la atribución para nombrarlos.

Alcauter concluye al respecto que hacia 1792 ya había tenientes de justicia en todas las subdelegaciones y que nunca se aplicó la medida dispuesta por la real ordenanza relativa a su supresión. Los tenientes actuaban como auxiliares de los subdelegados a quienes servían de vigilantes y de jueces receptores en las causas que se substanciaban en la subdelegación. Colaboraban con ellos en la recaudación de los tributos.

Volviendo a Chile, observamos que en los primeros años de implantación del régimen de intendencias, un tema recurrente fue el de la administración de justicia en las nuevas intendencias y subdelegaciones. Correspondió dilucidar este punto a la Junta Superior de Real Hacienda, creada por la real ordenanza de intendentes para establecer las intenden-

\footnotetext{
30 Arancibia et al. (2003) p. 17-18.

31 DOUGNAC (2006), p. 456.

32 Albornoz (2015).

33 Alcauter (2012).
} 
cias $^{34}$. A dicha junta el presidente de Chile, Ambrosio de Benavides, le consultó en 1786 sobre la posibilidad de que los subdelegados tuvieran facultad "de nombrar tenientes en los parajes distantes de la cabecera de su residencia con precedente aprobación de los respectivos intendentes" ${ }^{\prime 3}$. La Junta decidió consultar sobre este punto al rey y, mientras tanto, no hacer novedad:

"Por ahora con los tenientes de corregidor que actualmente sirven en los pueblos y lugares, hasta que el señor Presidente con informe de los subdelegados y Ayuntamiento si le pareciere, y con conocimiento sumario de causa de las distancias y poblaciones determine donde convenga, que a más de los subdelegados de nueva creación, deben también establecerse en lugar de los tenientes de corregidor los de subdelegado, o diputados, y proceda a elegirlos y librarles el correspondiente nombramiento, no para universalidad de causas, ni con jurisdicción ordinaria, si no con la que el derecho llama delegada para ciertos y limitados casos, con las modificaciones, restricciones o ampliaciones que pidan los territorios y particularidades de ellos ... Los cuales se expedirán con noticia del Real Acuerdo, justificando antes los que se hubiesen de elegir sus calidades, circunstancias, arraigo, y bienes o caudal suficiente para poder mantenerse sin auxilio de la Judicatura, ni pensionar al Público"36.

El tema de nombrar jueces subalternos del subdelegado no fue fácil de decidir. Inicialmente el visitador Escobedo pensó que, como en México, los tenientes de justicia de los corregidores "que eran los que administraban justicia en parajes distantes de las capitales para que no tengan que acudir a ella los que viven retirados" 37 , podían suprimirse dado que se multiplicarían las subdelegaciones. Sin embargo, en 1787 un expediente sobre el señalamiento de territorios para establecimiento de diputaciones en el partido de Colchagua, aclaraba más este punto. Junto con sostener que por decisión del Superintendente de Lima, se habían tolerado los tenientes de subdelegados en el virreinato del Perú y como, expresamente, la real ordenanza prohibía su nombramiento, se proponía que en Chile se mantuvieran estos jueces y que "será mejor declararles las facultades que ejercieron los tenientes de corregidores, y que se elijan por los subdelegados con precedente licencia de los respectivos intendentes" 38 , en los parajes distantes de las ciudades, no en ellas.

\footnotetext{
34 ARCHIVO NACIONAL - FONDO VARIOS 1028, Real Ordenanza para el establecimiento e instrucción de intendentes de ejército y provincia en el virreinato de Buenos Aires año 1782.

35 BIBLIOTECA NACIONAL- SALA MEDINA, tomo 197, rollo 39, Testimonio del expediente sobre establecimiento de gobierno de intendencias remitido por Ambrosio Benavides al Marqués de Sonora, 7 de octubre de 1786.

36 ARCHIVO NACIONAL - CAPITANÍA GENERAL 708, Expediente formado sobre el nuevo Establecimiento de la Superintendencia General de Real Hacienda e Intendencias del Reino de Chile, 1787.

37 ARCHIVO NACIONAL - CAPITANÍA GENERAL 708, Expediente formado sobre el nuevo Establecimiento de la Superintendencia General de Real Hacienda, e Intendencias del Reino de Chile, 1787.

38 ARCHIVO NACIONAL - CAPITANÍA GENERAL 939, Superintendencia año 1787 expediente sobre señalamiento de territorios para establecimiento de diputaciones en el partido de Colchagua con noticias y estado topográfico y de población de aquel distrito.
} 
Sin embargo, no quedó en manos de los subdelegados el nombramiento de los jueces diputados, sino que fue una atribución de los intendentes ${ }^{39}$. Efectivamente, los tenientes de corregidores habían sido nombrados por los corregidores para parajes distantes, mientras que los nuevos jueces diputados fueron nombrados en distritos territoriales, denominados diputaciones, delimitados y aprobados por la Junta Superior de Real Hacienda. Por tanto, las subdelegaciones chilenas se subdividieron en distritos al frente de los cuales hubo un juez diputado que no tenía todas las facultades de los subdelegados. No hemos encontrado en la documentación una definición precisa de juez diputado. Tampoco la bibliografía consultada de otros lugares de la América española da cuenta de este tipo de juez, con esta denominación, ni los define la bibliografía chilena que los nombra. No fueron tan solo los antiguos tenientes de corregidor con un nuevo nombre, como lo sostuvo María Teresa Co$\operatorname{bos}^{40}$, dado que los subdelegados reemplazaron a los corregidores y tenían otras funciones integradas en una nueva jerarquía administrativa. ¿Cómo los definieron las autoridades que los crearon? Creemos que es preciso considerar que hubo un proceso de decisión de establecerlos y que las facultades de estos jueces se fueron definiendo paulatinamente en general, pero fueron los intendentes, como veremos, los que decidieron en cada nombramiento qué facultades concedían.

Jorge de Escobedo, visitador del Perú, quien fue uno de los que planificó la implantación de las intendencias en Chile, propuso al virrey Teodoro de Croix en 1785, que los subdelegados continuaran con el mismo método que los corregidores "de diputar sujetos que a su nombre administren justicia a distancia de la capital de su residencia" ${ }^{41}$, aunque podía dudarse de que tuvieran para ello facultad. Diputar significaba elegir o designar a alguien para que desempeñara un ministerio o una función en nombre de otro. ¿Qué diferencia había entre un teniente de corregidor y un juez diputado? ¿Qué era un teniente? El Diccionario de Autoridades lo define como "el que ocupa y ejerce el cargo o ministerio de otro y es como sustituto suyo" ${ }^{42}$. Un teniente era un delegado de una autoridad superior. Las instrucciones enviadas por la Junta Superior el 23 de agosto de 1786 a todos los subdelegados afirmaba que:

"Se permite que subsistan los tenientes que eran de corregidor, con la denominación de Jueces Diputados, no para la universalidad de causas, ni con jurisdicción ordinaria, sino para celar los delitos públicos y escandalosos y el buen orden y régimen de los lugares, seguridad de las campañas y caminos, facción de testamentos, oír verbalmente en demandas civiles y deudas de corta entidad y valor, persecución y captura de delincuentes y malhechores, con la calidad de dar cuenta con la sumaria en todo lo criminal al Subdelegado del

\footnotetext{
39 ARCHIVO NACIONAL - CAPITANÍA GENERAL 708, Expediente formado sobre el nuevo Establecimiento de la Superintendencia General de Real Hacienda, e Intendencias del Reino de Chile, 1787.

40 CoBos (1986) p. 126.

41 ARCHIVO NACIONAL - FONDO MORLA VICUÑA 7, Carta de Jorge Escobedo a Teodoro de Croix, Lima 13 de diciembre de 1785.

42 DICCIONARIO DE AUTORIDADES (1739) Tomo VI.
} 
Partido, para los demás ocursos de esta semejanza que se ofrezcan en los territorios que tengan encomendados a su inspección”³3.

El texto, destinado a dar a conocer el nuevo régimen, aunque afirma que se mantenían los tenientes de corregidor con otra denominación, de inmediato traza la diferencia entre ambos. De la misma manera se afirmó que "en esta parte nada varía el nuevo sistema, sino el nombre de Subdelegados con que se conocerán ahora los que se han titulado Corregidores" ${ }^{4}$, lo que no significaba que había solo una mudanza de nombre.

Además, las facultades de los jueces diputados estaban definidas en su nombramiento, que estaba reservado a la Intendencia. Un nombramiento que ha llegado hasta nosotros se refiere a este juez como "teniente de subdelegado o juez diputado" ${ }^{45}$. El intendente debía consultar previamente al subdelegado sobre la idoneidad del sujeto, el que debía tener arraigo y poseer medios propios de subsistencia. Cada subdelegado de acuerdo con el cabildo de la ciudad cabecera, debía determinar justificadamente en qué lugares se establecerían los jueces. La Junta Superior de Real Hacienda emitió un oficio consultivo a los ayuntamientos para que se pronunciaran sobre la subsistencia de los tenientes de corregidor con el cambio de denominación y facultades. Ha llegado a nosotros la que se evacuó en San Fernando en octubre de 1786, firmada por los miembros del cabildo y el subdelegado, la que confirmaba la necesidad de mantener estos jueces. Manifestaron que el hecho de que el nombramiento del juez diputado lo hiciera el intendente y no el subdelegado, redundaría en un incumplimiento de sus funciones porque al no haber sido hechos jueces por el subdelegado, y no pudiendo este quitarles el empleo, se generarían causas ante el intendente. Mientras que los tenientes de corregidores se esmeraban en el desempeño de sus funciones para agradar a su jefe e impedir que este los removiera.

Pero en realidad, el punto del rechazo era otro, y se basaba en la experiencia con los jueces de comisión que inundaban los campos y "hoy se están viendo algunos jueces de comisión con títulos del Superior Gobierno que tienen más facultades que los abolidos corregidores" ${ }^{26}$, que hacían lo que querían sin reconocer superioridad en el Justicia Mayor de la Provincia.

\section{TENIENTES DE JUSTICIA DE LOS CORREgIDORES Y JUECES DE COMISIÓN}

Para profundizar más en las diferencias entre tenientes de corregidor y jueces diputados, vamos a detenernos en los jueces de comisión, los más cuestionados por el ayuntamiento de San Fernando. Su aparición estuvo unida al diagnóstico de un delito arraigado en todo Chile: el robo de ganado. El gobernador José Manso de Velasco fue el primero que

\footnotetext{
43 ARCHIVO NACIONAL - CAPITANÍA GENERAL 708, Expediente formado sobre el nuevo Establecimiento de la Superintendencia General de Real Hacienda, e Intendencias del Reino de Chile, 1787.

44 ARCHIVO NACIONAL - CAPITANÍA GENERAL 708, Expediente formado sobre el nuevo Establecimiento de la Superintendencia General de Real Hacienda, e Intendencias del Reino de Chile, 1787.

45 Ver un nombramiento en ARCHIVO NACIONAL - REAL AUDIENCIA 500, Instrucción que han de observar los Diputados que se nombrasen en el Distrito de la Jurisdicción del Partido de Colchagua dada por Tomás Álvarez de Acevedo, Santiago 3 de marzo de 1789.

46 ARCHIVO NACIONAL - CAPITANÍA GENERAL 939, Respuesta del cabildo de San Fernando a un oficio del Presidente de Chile, San Fernando 7 de octubre de 1786.
} 
afrontó el tema por medio de un bando en 1739, que imponía la pena de muerte a los culpables de robar al menos diez cabezas de ganado mayor o cinco de ganado menor. Ordenó "A todos los corregidores, sus lugartenientes, alcaldes ordinarios, provinciales de la Santa Hermandad, y generalmente a todos los jueces de las ciudades, villas y partidos de este reino", ${ }^{47}$ que persiguieran a los ladrones de ganado, previniéndolos que antes de aplicar la pena de muerte dieran cuenta a la Real Audiencia.

Varios años después, el problema del hurto de ganado no había variado. Un bando del gobernador Manuel de Amat y Junient de 1756 ordenó que: "Conviniendo proveer de remedio los continuos desordenes que se hacen en el campo, robando ganado de los dueños de hacienda y cometiendo otros ilícitos, he tenido por conveniente dar jurisdicción a estos para que puedan hacer sumarias, prender los reos y remitirlos presos, a las cárceles de las villas de su jurisdicción” ${ }^{48}$.

Por su parte, el gobernador Félix de Berroeta en 1761 determinó:

"Que en todos los corregimientos del reino por su dilatada extensión, señalen y deslinden ciertos, proporcionados distritos, y en cada uno de ellos nombrar persona de entera satisfacción y celo, para que con comisión particular de este superior gobierno e instrucción del fiscal persigan con eficacia y viveza a todo vagabundo y ladrón, fulminándoles sus causas y dándoles las demás providencias que se les advirtiesen en sus instrucciones, teniéndose presente para todo las declaraciones siguientes que debiendo ser acumulativa su jurisdicción con la de los corregidores y sus tenientes deberán estos por su parte, cumplir exactamente las obligaciones de su cargo, persiguiendo igualmente a todo ladrón y vagabundo y solo sobreseerán en las que ya conocieren los expresados comisionados con apercibimiento de que se les hará cargo en sus respectivas residencias si se justificare su omisión en punto de hallarse beneficio al bien común que evitando toda competencia cualquier comisionado podrá en el distrito de otro cualquiera aunque sea diverso corregimiento seguir y perseguir ahí al ladrón y delincuente que desde su jurisdicción solicita para su captura y si fuere necesario, mutuamente se auxiliaran todos los jueces para que mejor se haga el servicio de ambas majestades $^{49}$.

A partir de entonces comenzó el nombramiento sistemático de jueces de comisión para contener el robo de ganado. Según el Diccionario de Autoridades el juez de comisión es "Aquel a quien se comete alguna causa, o el conocimiento de ella, por el superior"50. De esta manera apareció una justicia delegada por la máxima autoridad real del territorio. No se recurrió a establecer más tenientes de corregidor o más alcaldes de la Hermandad, sino que a petición directa de los hacendados, ellos mismos o sus mayordomos se convirtieron en jueces.

\footnotetext{
47 ARCHIVO NACIONAL - CAPITANÍA GENERAL 406, Bando de José Manso de Velasco, Concepción 7 de enero de 1739.

48 ARCHIVO NACIONAL - CABILDO DE LA SERENA 18, Bando de Manuel Amat y Junient, Santiago 9 de abril de 1756.

49 ARCHIVO NACIONAL - CAPITANÍA GENERAL 406, Bando de Félix de Berroeta, Santiago 15 de diciembre de 1761.

50 DICCIONARIO DE AUTORIDADES (1734) Tomo IV.
} 
Con respecto a los tenientes de justicia de corregidor, debían ser nombrados por el Gobernador, según la Recopilación de Leyes de Indias ${ }^{51}$, sin embargo los testimonios apuntan en Chile al hecho de que era el corregidor quien los nombraba para los distritos distantes de las villas cabeceras de partido con el fin de llevar justicia al mundo rural. Convivieron con los jueces de comisión y cesaron en sus funciones a partir de 1786, con la implantación del régimen de intendencias.

Los jueces con comisión para perseguir ladrones en las haciendas se multiplicaron en la década de 1770 y se originaron en pedidos de particulares al gobernador para instituirlos. Cabe destacar que las comisiones no implicaban jurisdicción ordinaria ni podían atender causas de todo tipo. Tenían jurisdicción delegada, ponían en ejecución la comisión dada por el gobernador. Muchos hacendados pidieron que se nombraran jueces en sus haciendas, proponiéndose a sí mismos o a sus mayordomos, nombramientos que se hicieron para esos lugares específicos.

Confluyeron por tanto en el mundo rural diferentes justicias, cada una con su fuente de origen, delegadas de justicias mayores, que formaban parte de diferentes jerarquías. Se interrelacionaron entre sí, debatieron y pleitaron sobre su competencia. La integraban vecinos no profesionales del derecho que no recibían una remuneración. La recompensa era, sin duda, prestigio y autoridad local.

El canónigo de la catedral de Concepción Juan de la Roa y Guzmán pidió la comisión de juzgar para su mayordomo por el robo de 700 cabezas de ganado en los anteriores dos años, y que pudiera perseguir a los ladrones en el distrito, por diez leguas en torno ${ }^{52}$. Las comisiones podían darse para ser ejercidas también en una doctrina. "Se sirva nombrarme de juez de comisión de la doctrina de Longocura con facultad de perseguir los reos que maliciosamente se transportasen a otra doctrina" ${ }^{53}$, pedía Ángel Villalobos en 1773 al gobernador, quien lo nombró como juez de comisión con las facultades solicitadas. La petición del nombramiento generalmente iba acompañada de los méritos del solicitante, entre los que destacaban ser hacendado, el poseer algún grado en las milicias locales, y el ejercicio anterior de la judicatura, como haber sido teniente de corregidor, como lo recalcó el hacendado Lucas Guzmán, al pedir la comisión al gobernador para un vecino de su hacienda, antiguo teniente de corregidor, con la amplitud de poder perseguir delincuentes por todo el corregimiento ${ }^{54}$, lo que fue concedido. Además, hacían hincapié en que los jueces del partido estaban distantes y no actuaban por ello con la diligencia necesaria. El nombramiento de parte del gobernador puntualizaba que el comisionado podría perseguir a los ladrones con las milicias que comandaba.

\footnotetext{
51 RECOPILACIÓN DE LEYES DE INDIAS, libro 42, capítulo 5, número 5.

52 ARCHIVO NACIONAL - CAPITANÍA GENERAL 609, Petición de Juan de la Roa y Guzmán a Beltrán Balmaceda, del nombramiento de José Ibáñez como juez de comisión, Concepción, diciembre de 1768.

53 ARCHIVO NACIONAL - CAPITANÍA GENERAL 609, Petición de Ángel Gabriel de Villalobos, a Agustín Jáuregui, de recibir el nombramiento de juez de comisión, Santiago 13 de diciembre de 1773.

54 ARCHIVO NACIONAL - CAPITANÍA GENERAL 609, Petición de Lucas Guzmán a Ambrosio Benavides, para que se nombre juez de comisión a José Bernardino Saavedra, Santiago noviembre de 1785.
} 
Al nombramiento del juez de comisión precedía la petición por parte del interesado $y$, al concedérsele, se le precisaba que debían formar la sumaria y remitirla con el o los reos al corregidor ${ }^{55}$.

Estos nombramientos no pararon de hacerse hasta la implantación del régimen de intendencias en 1786. Lo que queremos destacar es el origen social de estos jueces, eran hacendados o sus mayordomos, por lo que podemos afirmar que a este grupo económico aumentó su autoridad en las zonas rurales a partir de 1770, en forma extraordinaria, lo que acrecentó su poder. La relación entre hacendados y judicaturas ya ha sido puesta de relieve inicialmente por María Teresa Cobos ${ }^{56}$. también por Rolando Mellafe en un artículo en el que reconstruye el proceso por el cual los hacendados adquirieron $\operatorname{poder}^{57} \mathrm{y}$, finalmente, por Alejandra Araya quien los menciona en algunos análisis de juicios en su estudio sobre el vagabundaje $\mathrm{e}^{58}$.

Vemos por tanto, que coexistieron los tenientes de justicia, nombrados por el corregidor que administraban justicia delegada, y los jueces de comisión, nombrados directamente por el Presidente de la Audiencia. Podemos por tanto afirmar que en el mundo rural coexistieron jueces nombrados por dos fuentes judiciales diferentes. Este era el panorama cuando, en 1786, la jurisdicción ordinaria, que antes detentaba el corregidor por delegación real, recayó en el intendente y su asesor letrado y en este último caso de manera independiente de la jurisdicción de los alcaldes ordinarios de los cabildos. Estos últimos eran jueces en un perímetro de cinco leguas desde la ciudad. Por otro lado, al cabo de dos o tres años, los jueces comisionados pidieron la confirmación en la comisión al intendente y muchos fueron convertidos en jueces diputados.

Con respecto a los tenientes de alcaldes de minas, estos continuaron existiendo debido a que la real ordenanza no los consideraba ni siquiera para suprimirlos. Sin embargo, una consulta de un alcalde de minas puso el tema ante la Superintendencia en 1787, al preguntar si se debía entender que los tenientes de alcaldes de minas continuaban o estaban agregados a las funciones de los jueces diputados de subdelegados. Se determinó que como era el intendente quien tenía la jurisdicción ordinaria en materia de minería, y se debía entender como delegada en el subdelegado y delegada, a la vez, en el juez diputado ${ }^{59}$. cesaban los tenientes de alcalde y recaía en los jueces diputados de subdelegados. Sin embargo, esta primera decisión no se mantuvo ya que la creación en Chile de la Real Administración de Minería instituyó diputados territoriales que administraban justicia y promovían la observancia de normas mineras en sus distri$\operatorname{tos}^{60}$.

\footnotetext{
55 ARCHIVO NACIONAL - CAPITANÍA GENERAL 609, Nombramiento de Miguel de Mujica como juez de comisión del corregimiento de Mendoza, Santiago, 27 de marzo de 1775.

56 Cobos (1980).

57 Mellafe (1981) p. 107.

58 ARAYA (1999).

59 ARCHIVO NACIONAL - CAPITANÍA GENERAL 252, pieza 16, Expediente sobre si con el establecimiento de Intendencias deben cesar en el ejercicio de su jurisdicción los tenientes de alcaldes mayores de minas, 1787.

60 Dougnac (1999) p. 118; Girón (2015).
} 


\section{Distritos y ATRIBUCIONES DE LOS JUECES DiPUTADOS}

Podemos decir por tanto que confluyeron en las nuevas diputaciones judiciales individuos con experiencia judicial, antiguos tenientes de corregidor y jueces de comisión. Se unificaron las judicaturas anteriores a la real ordenanza en un distrito judicial, un territorio en el que ejercía sus funciones un juez diputado, que era un juez delegado del intendente, quien ejercía jurisdicción ordinaria. Todas las subdelegaciones fueron divididas en dichos distritos, los que fueron determinados en su número y límites por la Junta Superior de Real Hacienda, luego de consulta hecha a los cabildos y subdelegados ${ }^{61}$. La subdelegación de Colchagua, por ejemplo, contó con 26 diputaciones aprobadas por la Superintendencia de Lima de $1787^{62}$. En la intendencia de Concepción había 215 jueces diputados en 1803, según Juan Martínez de Rozas, asesor letrado ${ }^{63}$. En la subdelegación de Maule se formaron 7 distritos $^{64}$. En 1788 había 8 en la subdelegación de Rancagua ${ }^{65}$.

Para ahondar más en las diferencias entre tenientes de justicia de los corregidores y los jueces diputados, necesitamos contraponer las facultades de los corregidores y los subdelegados en materias de justicia. Los primeros poseían jurisdicción ordinaria conferida de manera inmediata por el monarca, en causas de justicia y policía. Los subdelegados en Chile entendían en las cuatro causas (policía, justicia, hacienda y guerra) ${ }^{66}$ y ejercieron jurisdicción subdelegada del intendente, quien detentaba la justicia ordinaria. La Junta Superior de Real Hacienda determinó que los jueces diputados no tuvieran facultades para la universalidad de las causas "ni con jurisdicción ordinaria, si no con la que el derecho llama delegada para ciertos y limitados casos, con las modificaciones, restricciones o ampliaciones que pidan los territorios y particularidades de ellos" ${ }^{37}$.

¿Cuáles eran las atribuciones de los jueces diputados? Las instrucciones dictadas para los diputados del distrito de Colchagua en 1789 por la Superintendencia de Chile, extendidas a todas las diputaciones, las señalan. Los jueces diputados se debían ocupar del gobierno de su diputación tendiendo a la tranquilidad, paz, quietud y adelantamiento de la población. Debían administrar justicia y "celar y velar sobre los delitos que se cometiesen persiguiendo a los delincuentes hasta agotar y dejar libres los recintos de sus jurisdicciones

\footnotetext{
${ }_{61}$ ARCHIVO NACIONAL - CAPITANÍA GENERAL 549, Superintendencia, Expediente sobre señalamiento de territorios en que deban nombrarse Diputados para administración de Justicia del Partido de Rancagua, 1787.

62 ARCHIVO NACIONAL - CAPITANÍA GENERAL 939, Superintendencia año expediente formado de noticias territoriales del distrito diputación de Corcolen partido de San Fernando, 1787.

63 ARCHIVO NACIONAL - FONDO VARIOS 266, Informe de Juan Martínez de Rozas al fiscal de la Real Audiencia del 8 de junio de 1803.

64 ARCHIVO NACIONAL - CAPITANÍA GENERAL 1020, Informe de Juan Antonio Salcedo a Ambrosio Higgins, Talca 22 de enero de 1788.

65 ARCHIVO NACIONAL - CAPITANÍA GENERAL 658, Expediente formado sobre tomar razón de las rentas y propios de la villa de Santa Cruz del Partido de Rancagua y establecer ramos de arbitrios para ocurrir a sus urgencias públicas, Superintendencia año de 1788 .

66 ARCHIVO NACIONAL - CAPITANÍA GENERAL 708, Expediente formado sobre el nuevo Establecimiento de la Superintendencia General de Real Hacienda, e Intendencias del Reino de Chile, 1787.

${ }^{67}$ ARCHIVO NACIONAL - CAPITANÍA GENERAL 708, Expediente formado sobre el nuevo Establecimiento de la Superintendencia General de Real Hacienda, e Intendencias del Reino de Chile, 1787.
} 
de toda clase de ladrones, amancebadas, pendencieros, vagabundos, malentretenidos, y toda especie de malhechores que con sus depravadas y abominables costumbres contagian a los demás habitantes y hacen ilusorios los utilísimos fines que se aspira con el arreglo de estas diputaciones".

Procedían de oficio a recoger testimonios, proveer auto que sirviera de cabeza de proceso, proveían la sumaria, capturaban los reos y los enviaban a la Justicia inmediata para que los procesara. El auto debía iniciarse con la fecha y lugar, continuar con la denuncia o querella y, finalmente, incluir la sumaria información del contenido con comparecencia de testigos que tuvieran conocimiento del hecho. Concluido el auto, los jueces diputados debían firmarlo con testigos. Actuaban de oficio, por denuncia o querella verbal. Tenían facultades para oír y conocer en demandas verbales de hasta 20 pesos y resolverlas si las hallaban claras y fallar en justicia. Para la captura de los reos podían auxiliarse de los pobladores, a los que no les estaba permitido negarse bajo pena de ser castigados por inobediencia. Podían, asimismo, solicitar auxilio de otras justicias inmediatas. Su autoridad se extendía también a causas civiles y recibieron de hecho la tarea de ser ministros de fe pública que habían desarrollado los tenientes de corregidor.

Actuaban también como auxiliares de los subdelegados, supervigilando la construcción de obras públicas en su distrito; debían velar por el buen estado de los caminos y promover la industria, el comercio y la agricultura entre los pobladores. Pero su tarea principal era la judicial, por lo que podían nombrar jueces celadores para parajes distantes, con la aprobación de los subdelegados ${ }^{68}$. Debían mantener en paz y quietud a los habitantes de las campañas y reprimir "los hurtos, latrocinios y excesos de los malévolos y gentes malentretenidas con que se hallan infestados los territorios ... y sobre todo cuiden que los moradores del distrito que se les señalase separándose del detestable, y perjudicial vicio del ocio y abandono a que muchos de ellos se hallan entregados, y se apliquen a la cultura de las tierras, crías de ganados y al fomento de las demás venta del comercio, e industria" ${ }^{6}$.

Las facultades de los jueces diputados fueron variando según el tiempo y el lugar. Así lo señaló expresamente en 1804 el intendente de Concepción Luis de Álava, en autos con su asesor letrado, quien había removido a muchos jueces diputados durante un período que lo suplió. El intendente sostuvo que si bien las Instrucciones para el nombramiento de Jueces Diputados establecían que estos debían durar dos años en sus funciones, dicha medida era inaplicable por la falta de sujetos idóneos para el desempeño de la judicatura. Objetaba igualmente el intendente a su asesor que hubiera variado las facultades que habitualmente se les concedía, incorporando la de otorgar escrituras de venta y otros instrumentos públicos. Muchos jueces entregaban las matrices de escrituras a los interesados, favoreciendo

\footnotetext{
68 ARCHIVO NACIONAL-FONDO REAL AUDIENCIA 500, Instrucción que han de observar los Diputados que se nombrasen en el Distrito de la Jurisdicción del Partido de Colchagua dada por Tomás Álvarez de Acevedo, Santiago 3 de marzo de 1789.

69 ARCHIVO NACIONAL - FONDO VARIOS 266, Informe de Juan Martínez de Rozas al fiscal de la Real Audiencia del 8 de junio de 1803.
} 
toda clase de pleitos. Asimismo, el intendente objetaba que su asesor les hubiera concedido facultad de nombrar jueces celadores:

"Es necesario no tener el menor conocimiento de los habitantes de estas campañas para adaptar en esta parte las instrucciones que la conceden. ¿Si de aquellos Jueces Diputados de quienes se forma un regular concepto, no faltan al Gobernador Intendente repetidas representaciones de los subdelegados acusándolos de trato y comunicación con los ladrones y delincuentes, que excesos no cometerán en esta línea los celadores menos conocidos? ¿Y qué buenos efectos se pueden esperar de la multiplicación de jueces? ¿De unos jueces que es preciso adivinar para hacer sus nombramientos, y que rara vez se aciertan por la general corrupción de sus costumbres? No otra cosa que un desorden y cumulo de delitos, quedando impunemente los delincuentes a la sombra de estos mismos celadores" 70 .

La designación de los jueces celadores que hacían los jueces diputados debía contar con la aprobación del subdelegado, quien los nombraba y concedía las facultades, como en el caso de Jacinto de la Cruz en 1798 nombrado:

"Para que cele los delitos públicos y escandalosos y el buen orden de dichos lugares y la seguridad de las campañas y caminos de su comarca para la captura de los delincuentes, y malhechores los aprende, y de ellos de parte para su corrección, y pueda desempeñar las comisiones, y causas, que tengan a bien conferir sus superiores"71.

Las instrucciones a los subdelegados para el establecimiento, población y adelantamiento de las diputaciones dadas por Tomas Álvarez de Acevedo en 1788, permiten definir que las diputaciones eran parte esencial del proyecto borbónico de población y control del territorio. El estado monárquico reconocía que "En la recta administración de Justicia, arreglo y buen gobierno de los pueblos consiste principalmente su tranquilidad, paz, quietud y adelantamiento" y entregaba a los jueces diputados la tarea de imprimir con su ejemplo esas virtudes en la población.

Un objetivo fundamental del subdelegado era conseguir que la población dispersa en los campos se estableciera en pueblos o aldeas, en las que debía haber una parroquia o viceparroquia, allí debía residir el juez diputado, el estanquero o administrador de reales derechos y un maestro de escuela que enseñara a leer y escribir y la doctrina cristiana a los jóvenes. Los subdelegados debían cuidar que el empleo de juez diputado recayera en "sujetos de calidad, conducta y responsabilidad aunque no sean de los de primer orden haciéndoles la distinción y honor que corresponde para que no se retraigan de admitir estos encargos, sobrellevando esta carga como las demás de la república que deben soportar". Las instrucciones contemplan la posibilidad de que los vecinos se turnaran por dos años en el empleo, hasta que el crecimiento de los pueblos permitiera la creación de los alcaldes ordinarios ya que "inmediatamente que

\footnotetext{
70 ARCHIVO NACIONAL-FONDO JOSÉ VÍCTOR EYZAGUIRRE 3, Informe del Intendente de Concepción a Luis Muñoz de Guzmán, del 6 de diciembre de 1804.

71 ARCHIVO NACIONAL - CAPITANÍA GENERAL 600, Título de nombramiento de Jacinto de la Cruz como juez celador, dado por Manuel José Bravo de Naveda, Juez diputado de la doctrina de Chimbarongo, 15 de enero de 1798 .
} 


\section{haya proporción para ello se han de sustituir en lugar de los diputados con todas las facultades que a aquellos empleos corresponden"}

Como hemos dicho, los nombramientos de los jueces diputados los hacía el intendente o el asesor letrado. Pero muchas veces el subdelegado nombraba el juez y lo ponía en funciones, su servicio era de forma interina y debía pedir al intendente el nombramiento en propiedad ${ }^{73}$.

La Junta Superior de Real Hacienda determinó que los jueces diputados debían ejercer sus funciones por dos años. En algunos casos, cuando se había cumplido el plazo, el subdelegado procedía a nombrar un nuevo juez y solicitaba a la intendencia la confirmación ${ }^{74}$. El fondo Notarios del Archivo Nacional de Chile conserva los archivos de los jueces diputados. Una cata hecha en esa documentación nos permite afirmar que estos jueces podían ejercer sus funciones por décadas, como el caso de Miguel Escobar, juez diputado de Curicó ${ }^{75}$. Los jueces también fueron reemplazados por quejas de los vecinos sobre el deficiente ejercicio de la judicatura, por lo que el subdelegado procedía a suspender al juez y nombrar otro en forma interina, solicitando posteriormente el nombramiento en propiedad a la intendencia ${ }^{76}$. Observamos mucha libertad por parte de los subdelegados para destituir y nombrar nuevos jueces. Tal fue el caso de Vicente de la Cruz, subdelegado de Talca, quien removió a dos jueces por indolencia en sus funciones y nombró a otros dos que fueron confirmados por el asesor letrado. Ambos, sin embargo, no aceptaron los cargos por estar muy ocupados en sus haciendas ${ }^{77}$.

Hemos señalado la relación entre juez de comisión y hacendados. ¿Cómo fue la relación de los hacendados con los jueces diputados? La temática aparece en numerosas fuentes. Los cabildantes de San Fernando, en su declaratoria sobre la sustitución de los tenientes de justicia por los jueces diputados de 1786, ya mencionada, opinaban que "tal vez no habría sujetos de la instrucción y calidades los que debían tener dichos empleos porque de los principales hacendados ninguno ha querido obtener el empleo antiguo de teniente de corregidor y ahora lo apreciaran menos por las limitadas facultades que les quedan por jueces diputados considerando que estos son unos meros sirvientes del público"78.

\footnotetext{
72 ARCHIVO NACIONAL-CAPITANÍA GENERAL 939, Instrucción que ha de observar el subdelegado de Colchagua para facilitar el arreglo, población y adelantamiento de las diputaciones comprendidas en el distrito de su jurisdicción, Santiago 2 de mayo de 1788, Tomas Álvarez de Acevedo.

73 ARCHIVO NACIONAL - CAPITANÍA GENERAL 609, Petición de José Félix Brandique a José Rezabal Ugarte para que se le conceda el título de juez propietario, 25 de octubre de 1796.

74 ARCHIVO NACIONAL - CAPITANÍA GENERAL 609, Carta de Rafael Eugenio Muñoz a Luis Muñoz Guzmán solicitando la confirmación de Teodoro Valenzuela como juez diputado de Colchagua, San Fernando 5 de mayo de 1804

75 ARCHIVO NACIONAL-Notarios, Curicó 006, firma en varias actas.

76 ARCHIVO NACIONAL - CAPITANÍA GENERAL 609, Carta de Ignacio González Sotomayor a Luis Muñoz Guzmán, Quillota 18 de diciembre de 1805.

77 ARCHIVO NACIONAL - CAPITANÍA GENERAL 598, Expediente formado por Don Juan Garcés pretendiendo eximir del cargo de diputados de las doctrinas de Vichuquén y Paredones a Don Juan Enrique Garcés y Don Miguel de Rojas, Santiago diciembre 1791.

78 ARCHIVO NACIONAL - CAPITANÍA GENERAL 939, Respuesta del cabildo de San Fernando a un oficio del Presidente de Chile, San Fernando 7 de octubre de 1786.
} 
Sin embargo, la relación entre hacendados y jueces diputados queda testificada por muchas otras fuentes. Muchos hacendados fueron nombrados jueces diputados, aunque otros lo rechazaron; algunos proponían directamente a gente de su confianza para el empleo de juez diputado ${ }^{79}$. En la memoria de su gobierno, el Marqués de Avilés en 1797 señaló que como los subdelegados residían en las villas nombraban "para distribuir sus órdenes y administrar justicia" los jueces de distrito que residían en alguna hacienda "como este juez subsidiario es subalterno subdelegado no quieren admitir este cargo los hacendados y es preciso que la comisión recaiga en algunos infelices y algunas veces en mayordomos de haciendas. Por esta mera descripción es evidencia de las torpezas en que incurrirán por ignorancia o malicia unos hombres sin cultura ni comodidades que los pongan en algún modo a cubierto del cohecho o de la dependencia de los ricos, y cuan expuesta está a perecer la justicia de los pobres, siendo lo más sensible que este mal es irremediable" ${ }^{80}$.

En 1802 el subdelegado de Curicó informaba que la justicia rural era muy deficiente: "No hay diputación que no esté llena de ladrones, sin que los jueces diputados, que por otra parte tienen que atender a sus haciendas y ministerios para mantenerse, puedan formar tantas sumarias, prender tantos delincuentes, mantener muchísimas prisiones y tomar las providencias concernientes al caso" ${ }^{11}$.

En 1804 el asesor letrado de Concepción, en un informe sobre el mal funcionamiento de la justicia sostenía que muchos jueces diputados "excusaban su inacción diciendo que no perseguían a los malhechores porque luego salían en libertad y en venganza les robaban y destruían sus haciendas" 82 .

\section{LOS JUECES DiPUTAdOS A PARTIR DE 1810}

El año de 1810 marca un mojón de separación, según la historiografía americana en general, entre la Monarquía y el inicio de la construcción de los nuevos estados republicanos independientes. La autonomía de los territorios americanos se definió fundamentalmente frente a las autoridades surgidas por la acefalía monárquica en el pilar europeo de la Monarquía. Lo que sabemos de los gobiernos y las elites provinciales en este proceso, es la actitud frente a las juntas. Si miramos lo que la historiografía nos enseña sobre los años posteriores a 1810, todo parece estar dominado por el cambio. ¿Es posible afirmar que solo por la jura de fidelidad a las juntas de gobierno se garantizó el control del territorio que se definió como autónomo? Las discusiones de cómo reformar el gobierno y de cómo erigir y

\footnotetext{
79 ARCHIVO NACIONAL - CAPITANÍA GENERAL 598, Expediente formado por Don Juan Garcés pretendiendo eximir del cargo de diputados de las doctrinas de Vichuquén y Paredones a Don Juan Enrique Garcés y Don Miguel de Rojas, Santiago, diciembre 1791; ARCHIVO NACIONAL - CAPITANÍA GENERAL 609, Carta de Juan Antonio Armas a Luis Muñoz Guzmán informándole del nombramiento Juan Nicolás Santelices como juez diputado de la doctrina de Vichuquén, Curicó 22 de noviembre de 1802; ARCHIVO NACIONAL - CAPITANÍA GENERAL 605, Carta a Ramón Martínez de Rozas de los hacendados de los partidos de Lampa y Chicauma, septiembre 1794.

80 ANALES DE LA UNIVERSIDAD DE CHILE (1875): p. 448-449.

${ }^{81}$ ARCHIVO NACIONAL- REAL AUDIENCIA 2132, pieza 1, Informe de Juan Antonio Armas, a Luis Muñoz Guzmán, Curicó1802.

82 ARCHIVO NACIONAL- FONDO EYZAGUIRRE 3, Representación del señor Don Juan Martínez de Rozas a Luis Muñoz Guzmán, Concepción 18 de agosto de 1804.
} 
constituir el estado parecen dominar todo el espectro político. Pero mientras esto sucedía, mientras se debatía sobre cómo establecer un nuevo gobierno: ¿qué autoridades ejercían efectivamente el poder? No nos referimos solo a lo que ocurría en las capitales sede de las juntas, sino en el resto del territorio sobre el cual gobernaban.

A partir de 1810, no se modificó el gobierno interior de Chile con respecto al régimen de intendencias borbónico ${ }^{83}$. De hecho, el artículo 13 del Reglamento Constitucional Provisorio de 1812 mencionaba expresamente que la población debía jurar la observancia del reglamento ante los jueces territoriales, es decir subdelegados y jueces diputados. Señalaba expresamente que "la facultad judiciaria residirá en los tribunales y jueces ordinarios" $"$. El nombramiento del juez diputado de Quilicura de 1813 por el teniente letrado de la intendencia de Santiago, confirma la continuidad del sistema ${ }^{85}$.

La única modificación del régimen de gobierno interior del territorio de Chile, ahora autónomo, no fue una novedad absoluta. Nos referimos a la creación de la intendencia de Coquimbo por parte del Congreso Nacional de 1811, ya prevista por la Monarquía ${ }^{86}$. Por lo que creemos que podemos afirmar que, a partir de 1810, no se modificó el gobierno interior de Chile con respecto al régimen de intendencias borbónico. La continuidad del régimen de intendencias estuvo resguardada, desde luego, durante el período de restauración monárquico (fines de 1814-principios 1817).

Podemos ilustrar el proceso con el nombramiento de Juez Diputado de Chimbarongo de José María Ramírez, cuyo expediente nos permite transitar por varios de los sucesivos gobiernos desde 1810. Su primer nombramiento como diputado de aquel distrito lo hizo el subdelegado de Colchagua, José María Vivar, el 2 de julio de 1810. En 1813, el mismo subdelegado lo nombró juez diputado subrogante de su propio hermano, Jacinto de la Cruz Ramírez, en la diputación de Tinguiririca. En 1817 la comisión para la organización de los gobiernos subalternos del sur de Chile, formada en febrero por el Director Supremo Bernardo O’Higgins, e integrada por Juan Francisco Larraín, Diego Donoso y Francisco Egidio de la Cuadra ${ }^{87}$, consideró que como:

"Concurren en Don José María Ramírez las calidades de acendrado patriotismo, actividad y justificación notoria le nombramos interinamente de Ministro Diputado de Justicia en el lugar de Chimbarongo para que como a tal se le reconozca y respete ... en el ejercicio de su empleo, cuya extensión y facultades serán las que le sean asignadas por el superior gobierno del estado en la confirmación que obtenga de este título y conforme al artículo $4^{\circ}$ de la instrucción en nuestra comisión empezará a ejercer inmediatamente sus funciones" 88 .

En Chile, hasta la declaración de la independencia en 1818 no hubo ningún intento de reformar el régimen de intendencias implantado en 1786. El Reglamento

83 Dougnac (2000) p. 236.

84 Anguita y Quesney (1902) Tomo I, p. 34.

85 ARCHIVO NACIONAL-CAPITANÍA GENERAL 182, Nombramiento de Diputado de Quilicura en Don Manuel Ramírez, 1813.

86 Cobos (1989) p. 34.

87 ARCHIVO DE DON BERNARDO O'HIGGINS, Tomo XVII, p. 140.

88 ARCHIVO NACIONAL-CAPITANÍA GENERAL 144, Expediente sobre el nombramiento de José María Ramírez como juez diputado de Chimbarongo, 1817. 
Constitucional de 1818 dividió e territorio en tres provincias (Concepción, Santiago y Coquimbo), según el art. 1. Se mantuvieron los gobernadores intendentes que junto con sus tenientes eran jueces ordinarios (cap. IV, art. 2). Subsistieron los jueces diputados, pero se varió la forma de nombrarlos con respecto a la usanza monárquica:

"A los Tenientes Gobernadores corresponde el nombramiento de los jueces diputados de su partido, y observarán escrupulosamente la conducta de estos y sus celadores, a fin de hacerlos cumplir con sus deberes, y que no sean oprimidos los pobres, cuya indigencia exige con preferencia la protección de los Gobiernos" (artículo 9, cap. IV) ${ }^{89}$.

\section{CONCLUSIONES}

Luego de décadas de estudio sobre las reformas borbónicas en virreinatos y capitanías, nuestro trabajo se inscribe en la línea de conocer más la implantación de estas reformas en las periferias del imperio. Los jueces diputados de subdelegados y sus distritos ofrecen un nuevo campo de análisis no solo de las judicaturas sino también de las zonas en las que el Estado monárquico no tuvo control efectivo hasta la creación del régimen de intendencias. El tema, sin duda, no está agotado con este artículo. La comparación del caso chileno con el virreinato del Río de la Plata, nos permite marcar una diferencia notoria. Mientras en Chile la justicia rural se desarrolló más a partir de la implantación del régimen de intendencias, en el Río de la Plata dicho desarrollo estuvo vinculado a los cabildos.

Hemos trazado un primer panorama sobre la justicia distrital, rural en Chile a partir de 1786. El juez diputado emerge como una figura fundamental del gobierno de la Monarquía en el proceso de control del territorio. No solo fueron auxiliares de la justicia que ejercía el subdelegado en la medida en que les fueron entregadas esas facultades, sino que cumplían funciones administrativas. La racionalización de la distribución de estos jueces, auxiliados por los jueces celadores, en distritos trazados y aprobados por la Junta Superior de Real Hacienda, su cantidad y distribución, nos permite concluir que eran el eslabón inicial de la cadena de justicia subalterna. En el juez diputado llegaba a cada rincón del territorio el estado monárquico, tomando posesión efectiva del mismo, adquiriendo presencia, conocimiento real de la población. Su localización, en muchos casos, en doctrinas y parroquias, hacía presente a ambas majestades en rincones del mundo rural que, a raíz de este proceso, aparecen como desprovistos de autoridades. Precisamente allí era necesaria, desde la óptica monárquica, establecer ambas jurisdicciones al servicio de poblaciones que no estaban dentro del gobierno efectivo de la Monarquía. Tomar posesión de esos territorios y controlar a los habitantes que vivían allí, calificados de vagos y delincuentes, acercarlos a la civilización, era el objetivo fundamental que motivó la multiplicación de jueces controlados directamente por el Presidente de la Audiencia. El origen social de los jueces diputados, hacendados o sus mayordomos, profundizó el control territorial que estos tenían y que fueron adquiriendo con la protección gubernamental a lo largo del siglo XVIII. En este sen-

89 Anguita y Quesney (1902) Tomo I, p. 58-60. 
tido, no se creó una nueva elite social rural, sino que la que ya existía adquirió más poder, de hecho podemos afirmar que la justicia rural funcionó directamente en las haciendas o estrechamente ligado a ellas. El vínculo entre hacendado y justicia ya se había establecido a lo largo del siglo XVIII a través de la justicia comisionada por el Presidente de Chile y tuvo continuidad en el juez diputado.

El régimen de intendencias, subdelegaciones y jueces distritales no fue alterado a partir de 1810. Después de la declaración de la independencia en 1818 se mantuvo en los sustancial, lo que nos permite afirmar que su continuidad garantizó la gobernabilidad del territorio en aquellos tiempos de cambios y de guerra.

\section{BIBLIOGRAFÍA CITADA}

Albornoz, María Eugenia (2015): “Autoridades locales conflictuadas: temores y dificultades de jueces territoriales en Chile colonial (1711-1817)”. Disponible: http://nuevomundo. revues.org/68292. Fecha de consulta: 28 de octubre de 2015

Alcauter, José Luis (2012): Régimen de subdelegaciones en la América Borbónica. Autoridades intermedias en transición (Valladolid de Michoacán, El Colegio de Michoacán, tesis doctoral inédita).

Altable, Francisco (2013): Vientos nuevos. Idea, aplicación y resultados del proyecto borbónico para la organización del gobierno y el desarrollo de la población y economía de las Californias, 1767-1825 (México, Universidad Autónoma de Baja California, primera edición).

Anales de la universidad de Chile (1875): "Historia de Chile. Relación de gobierno que dejó el señor marqués de Avilés, presidente de Chile, a su sucesor del señor Don Joaquín del Pino (1796-1797)". Disponible en http://www.anales.uchile.cl/index.php/ ANUC/article/viewFile/19375/20488. Fecha de consulta: 29 de diciembre de 2015.

Anguita, Ricardo y Quesney, Valerio (1902): Leyes promulgadas en Chile desde 1810 hasta 1902 inclusive. Disponible en https://ia801901.us.archive.org/25/items/leyespromulgada00chilgoog/leyespromulgada00chilgoog.pdf. Fecha de consulta: 10 de diciembre de 2015.

Arancibia Floody, Claudia; Cornejo Cancino, José Tomás; González undurraga, Carolina (2003): Pena de muerte en Chile colonial: cinco casos de homicidio de la Audiencia Real (Santiago, RIL editores, primera edición).

Archivo de don Bernardo O’ Higgins - Tomo XVII.

Archivo Nacional - Cabildo de La Serena 18, Bando de Manuel Amat y Junient, Santiago, 9 de abril de 1756.

Archivo Nacional - Capitanía General 144, Expediente sobre el nombramiento de José María Ramírez como juez diputado de Chimbarongo, 1817.

Archivo Nacional - Capitanía General 182, Nombramiento de Diputado de Quilicura en Don Manuel Ramírez, 1813.

Archivo Nacional - Capitanía General 252, Expediente sobre si con el establecimiento de Intendencias deben cesar en el ejercicio de su jurisdicción los tenientes de alcaldes mayores de minas, 1787. 
Archivo Nacional - Capitanía General 406, Bando de José Manso de Velasco, Concepción, 7 de enero de 1739; Bando de Félix de Berroeta, Santiago, 15 de diciembre de 1761.

Archivo Nacional - Capitanía General 549, Superintendencia, Expediente sobre señalamiento de territorios en que deban nombrarse Diputados para administración de Justicia del Partido de Rancagua, año 1787.

Archivo Nacional - Capitanía General 598, Expediente formado por Don Juan Garcés pretendiendo eximir del cargo de diputados de las doctrinas de Vichuquén y Paredones a Don Juan Enrique Garcés y Don Miguel de Rojas, Santiago, diciembre 1791.

Archivo Nacional - Capitanía General 600, Título de nombramiento de Jacinto de la Cruz como juez celador, dado por Manuel José Bravo de Naveda, Juez diputado de la doctrina de Chimbarongo, 15 de enero de 1798.

Archivo Nacional - Capitanía General 605, Carta a Ramón Martínez de Rozas de los hacendados de los partidos de Lampa y Chicauma, septiembre 1794.

Archivo Nacional - Capitanía General 609, Nombramiento de Miguel de Mujica como juez de comisión del corregimiento de Mendoza, Santiago, 27 de marzo de 1775; Petición de Juan de la Roa y Guzmán a Beltrán Balmaceda del nombramiento de José Ibáñez como juez de comisión, Concepción, diciembre de 1768; Petición de Ángel Gabriel de Villalobos a Agustín Jáuregui de recibir el nombramiento de juez de comisión, Santiago, 13 de diciembre de 1773; Petición de Lucas Guzmán a Ambrosio Benavides, para que se nombre juez de comisión a José Bernardino Saavedra, Santiago, noviembre de 1785; Petición de José Félix Brandique a José Rezabal Ugarte, para que se le conceda el título de juez diputado propietario, 25 de octubre de 1796; Carta de Juan Antonio Armas a Luis Muñoz Guzmán, informándole del nombramiento Juan Nicolás Santelices como juez diputado de la doctrina de Vichuquén, 22 de noviembre de 1802; Carta de Rafael Eugenio Muñoz a Luis Muñoz Guzmán solicitando la confirmación de Teodoro Valenzuela como juez diputado de Colchagua, San Fernando el 5 de mayo de 1804; Carta de Ignacio González Sotomayor a Luis Muñoz Guzmán, Quillota, 18 de diciembre de 1805.

Archivo Nacional - Capitanía General 658, Expediente formado sobre tomar razón de las rentas y propios de la villa de Santa Cruz del Partido de Rancagua y establecer ramos de arbitrios para ocurrir a sus urgencias públicas, año de 1788.

Archivo Nacional - Capitanía General 708, Expediente formado sobre el nuevo Establecimiento de la Superintendencia General de Real Hacienda e Intendencias del Reino de Chile, 1787.

Archivo Nacional - Capitanía General 939, Respuesta del cabildo de San Fernando a un oficio del Presidente de Chile, San Fernando, 7 de octubre de 1786; Expediente sobre señalamiento de territorios para establecimiento de diputaciones en el partido de Colchagua con noticias y estado topográfico y de población de aquel distrito, Superintendencia año 1787; Expediente formado de noticias territoriales del distrito diputación de Corcolen partido de San Fernando, Superintendencia año 1787; Instrucción que ha de observar el subdelegado de Colchagua para facilitar el arreglo, población y adelantamiento de las diputaciones comprendidas en el distrito de su jurisdicción, Santiago 2 de mayo de 1788, Tomas Álvarez de Acevedo. 
Archivo Nacional - Capitanía General 1020, Informe de Juan Antonio Salcedo a Ambrosio Higgins, Talca 22 de enero de 1788.

Archivo Nacional - Fondo José Víctor Eyzaguirre 3, Representación del Señor Don Juan Martínez de Rozas a Luis Muñoz Guzmán, Concepción 18 de agosto de 1804; Informe del Intendente de Concepción a Luis Muñoz de Guzmán, 6 de diciembre de 1804.

Archivo Nacional - Fondo Morla vicuña 7, Carta de Jorge Escobedo a Teodoro de Croix, Lima 13 de diciembre de 1785.

Archivo Nacional - Fondo varios 266, Informe de Juan Martinez de Rozas, al fiscal de la Real Audiencia, 8 de junio de 1803.

Archivo Nacional - Fondo varios 1028, Real Ordenanza para el establecimiento e instrucción de intendentes de ejército y provincia en el virreinato de Buenos Aires, 1782.

Archivo Nacional - Real Audiencia 500, Instrucción que han de observar los Diputados que se nombrasen en el Distrito de la Jurisdicción del Partido de Colchagua dada por Tomás Álvarez de Acevedo, Santiago 3 de marzo de 1789.

Archivo Nacional - Real Audiencia 2132, Informe de Juan Antonio Armas a Luis Muñoz Guzmán, Curicó 1802.

Archivo Nacional - Notarios, curicó 006, Firma en varias actas.

AraYA, Alejandra (1999): Ociosos, vagabundos y malentretenidos en Chile colonial (Santiago, LOM ediciones, primera edición).

Barriera, Darío y Dalla Corte, Gabriela (2001): "La Ventana Indiscreta. La Historia y la Antropología Jurídica a través de la emoción de sus textos", Prohistoria, No 5: pp. 11-14.

BARriera, Darío (2012): "Instituciones, justicias de proximidad y derecho local en un contexto reformista: designación y regulación de "jueces de campo" en Santa Fe (Gobernación-Intendencia de Buenos Aires) a fines del siglo XVIII", Revista de Historia del Derecho, No 44, pp. 1-28.

BengoA, José (1990): Historia social de la agricultura chilena, Tomo I (Santiago, Editorial SUR).

Biblioteca nacional - Sala Medina, tomo 197, rollo 39, Testimonio del expediente sobre establecimiento de gobierno de intendencias remitido por Ambrosio Benavides al Marqués de Sonora, Santiago 7 de octubre de 1786.

Bravo Lira, Bernardino (1986): Historia de las instituciones politicas de Chile e Hispanoamérica (Santiago, Editorial Jurídica, primera edición).

Bravo Lira, Bernardino (1994): El absolutismo ilustrado en Hispanoamérica. Chile (17601860), de Carlos III a Portales y Montt (Santiago, Editorial Universitaria, primera edición).

Coвos, María Teresa (1980): "La institución del juez de campo en el reino de Chile durante el siglo XVIII", Revista de Estudios histórico Jurídicos", No 5: pp. 85-165.

Cobos, María Teresa; Lorenzo, Santiago (1985): "Esquema de la administración de justicia en las áreas rurales chilenas, 1700-1786", Revista de Derecho de la Pontificia Universidad Católica de Valparaíso, No 9: pp. 65-88.

Совоs, María Teresa (1986): "Notas para el estudio de las Intendencias en Chile indiano", Revista de Estudios histórico-jurídicos, Vol. 11: pp. 109-141.

Diccionario DE AUTORIDAdes (1736): Tomo IV (Madrid, Real Academia Española) 
Diccionario de autoridades (1739): Tomo VI (Madrid, Real Academia Española)

Diego Fernández Sotelo, Rafael; Gutiérrez Lorenzo, María Pilar; Arrioja Díaz ViRUELL, Luis Alberto (2014): De reinos y subdelegaciones. Nuevos escenarios para un nuevo orden en la América Borbónica (México, El Colegio de Michoacán, Universidad de Guadalajara, El Colegio Mexiquense, primera edición).

Dougnac, Antonio (1981): "La real administración del importante cuerpo de minería de Chile (1787-1802)", Revista Chilena de Historia del Derecho, No 8: pp. 109-130.

Dougnac, Antonio (1985): "El cabildo y el derecho de aguas en Santiago en los siglos XVII y XVIII", Revista Chilena de Historia del Derecho, N 11: pp. 277-133.

Dougnac, Antonio (2000): "El sistema jurídico indiano en el constitucionalismo chileno durante la patria vieja (1810-1814)", Revista de Estudios Histórico-Jurídicos, № 22: pp. 225-266.

Dougnac (2006): "Los principios clásicos del procedimiento y la palabra hablada en el sistema jurídico indiano. El estilo de Chile", Revista de Estudios Histórico-Jurídicos, $\mathrm{N}^{\circ}$ 28: pp. 425-490.

FradKIn, Raúl (2009): "La experiencia de la justicia: Estado, propietarios y arrendatarios en la campaña bonaerense (1800-1830), en FradKIn, Raúl (coord.), La ley es tela de araña. Ley, justicia y sociedad rural en Buenos Aires, 1780-1830 (Buenos Aires, Prometeo).

Fradkin, Raúl; Barral, María Elena; Perri, Gladys; y Alonso, Fabián (2007): "Los vagos en la campaña bonaerense: la construcción histórica de una figura delictiva (17301830)”, en Fradkin Raúl (comp.), El poder y la vara. Estudios sobre la justicia y la construcción del estado en el Buenos Aires rural (Buenos Aires, Prometeo).

Fradkin, Raúl; Barral, María Elena; Perri, Gladys; y Alonso, Fabián (2007): “¿Quiénes son los "perjudiciales"? Concepciones jurídicas, producción normativa y práctica judicial en la campaña bonaerense (1780-1830)", en FradKIn, Raúl (comp.), El poder y la vara. Estudios sobre la justicia y la construcción del estado en el Buenos Aires rural (Buenos Aires, Prometeo, primera edición).

Garavaglia, Juan Carlos (1999): "Alcalde de la Hermandad et Juges de paix á Buenos Aires (XVIIIe-XIX siecle)”, Études rurales, Vol. 149, No 1: pp. 99-110.

Góngora, Mario (1966): "Vagabundaje y sociedad fronteriza en Chile (siglos XVII a XIX)", Cuadernos del Centro de Estudios socieconómicos, No 2: pp. 1-41.

GIRÓN ZÚNIGA, Nicolás (2015): Los jueces y el poder en el norte chico. Una aproximación a la trama politica y económica de una sociedad en formación (Santiago, Tesis para optar al grado de Magister en Historia, Universidad de Chile).

GÓngOra, Mario (1966): "Vagabundaje et société en Amerique latine (specialmente au Chili central)", Annales, économies, sociétés, civisations, No 1: pp. 159-177.

Izard, Miquel (1981): "Ni cuatreros ni montoneros, llaneros", Boletín Americanista, No 31: pp. 83-142.

IZARD, Miquel (1987): "Sin el menor arraigo ni responsabilidad. Llaneros y ganadería a principios del siglo XIX”, Boletín Americanista, No 37: pp. 109-142.

LeTELier, Valentín (1889): Sesiones de los cuerpos lejislativos de la República de Chile: 18111845, Tomo IX (Santiago, Imprenta Cervantes). 
Letelier, Valentín (1899): Sesiones de los cuerpos legislativos de la República de Chile: 1811 1845, Tomo XX (Santiago, Imprenta Cervantes).

Lorandi, Ana María (2008): Poder central, Poder local. Funcionarios Borbónicos en el Tucumán colonial. Un estudio de Antropología Política (Buenos Aires, Prometeo, primera edición).

Lorenzo, Santiago (1999): "El corregidor chileno en el siglo XVIII", Revista Historia, No 32: pp. 131-139.

LyNCH, John (1996): "El reformismo Borbónico e Hispanoamérica”, en GuimerÁ, Agustín (edit.), El reformismo borbónico. Una visión interdisciplinar (Madrid, Alianza) pp. 37-70.

LYNCH, John (2001): Las revoluciones Hispanoamericanas 1808-1826 (Barcelona, Ariel, nueva edición ampliada y puesta al día).

Martin, Norman (1957): Los vagabundos en la Nueva España. Siglo XVI (México, Jus, primera edición).

Martínez Baeza, Sergio (1995): "La fe pública y la costumbre en el Chile indiano", Revista de Estudios Histórico Jurídicos, No 17: pp. 285-292.

Martínez Dougnac, Gabriela (1996): "Justicia colonial, orden social y peonaje obligatorio", en AzCuY, Eduardo (edit.), Poder terrateniente, relaciones de producción y orden colonial, (Buenos Aires, Fernando García Cambeiro) pp. 185-225.

MaYo, Carlos (1987): "Sobre peones, vagos y malentretenidos: el dilema de la economía rural rioplatense durante la época colonial”, Anuario del IEHS, N² 2: pp. 25-32.

MaYo, Carlos (1989): "Entre el trabajo y el "ocio": vagabundos de la llanura pampeana (1750-1810)", HISLA, No XIII-XIV: pp. 67-76.

MolinA, Eugenia (2011): “Trayectorias judiciales, movilidad social y vida pública. Los jueces inferiores en Mendoza, 1770-1810”, en Polimene, María Paula (coord.), Autoridades y prácticas judiciales en el Antiguo Régimen. Problemas jurisdiccionales en el Río de la Plata, Córdoba, Tucumán, Cuyo y Chile (Rosario, Prohistoria).

Morazzani de Pérez Enciso, Gisela (1966): La intendencia en España y en América (Caracas, Universidad Central de Venezuela, primera edición).

Mellafe, Rolando (1981): "Latifundio y poder en Chile de los siglos XVII y XVIII", Cuadernos de Historia, No 1: pp. 87-108.

Muñoz, Juan G.; Adunka, Michelle (2015): "Actas del cabildo de la villa de San Agustín de Talca (Reino de Chile, 1759-1815)", Revista Iberoamericana de Viticultura, agroindustria y ruralidad, Vol. 2, No 5: pp. 156-265.

Navarro, Luis (1959): Intendencias en Indias (Sevilla, Escuela de Estudios Hispanoamericanos, primera edición).

Navarro, Luis (1995): Las reformas borbónicas en América. El plan de intendencias y su aplicación (Sevilla, Universidad de Sevilla, primera edición).

Navarro, Luis (2005): "La élite frente a la intendencia y el corregimiento en la ciudad de México”, en García Bernal, Manuela; Navarro García, Luis; Ruiz Rivera, Julián (comp.), Elites urbanas en Hispanoamérica (Sevilla, Universidad de Sevilla) pp. 163-174.

NaVArRo, Luis (2009): Servidores del Rey. Los intendentes de Nueva España (Sevilla, Universidad de Sevilla, primera edición). 
Ortelli, Sara (2006): "Las reformas borbónicas vistas desde la frontera. La elite neovizcaína frente a la injerencia estatal en la segunda mitad del siglo XVIII", Boletín del Instituto de Historia Argentina y Americana Dr. Emilio Ravignani, No 28: pp. 7-37.

Pérez Estévez, Rosa (1976): El problema de los vagos en la España en el siglo XVIII (Madrid, Confederación española de Cajas de Ahorro, primera edición).

Pietschmann, Horst (1996): Las reformas Borbónicas y el sistema de intendencia en Nueva España. Un estudio político administrativo (México, Fondo de Cultura Económica, primera edición en español).

Recopilación de Leyes de Indias (1680), (Madrid, edición por Julián de Paredes).

Reyes Cárdenas, Ana Catalina; Montoya Guzmán, Juan David y Gómez González, Sebastián (2013): El siglo XVIII americano. Estudios de historia colonial (Medellín, Facultad de Ciencias Humanas y Económicas, sede Medellín Universidad Nacional de Colombia, primera edición).

SANHUEZA, Carolina (2008): "La primera división político-administrativa de Chile (18111826)", Revista Historia, No 41: pp. 447-493.

Tío VAllejo, Gabriela (1998): "La "buena administración de justicia” y la autonomía del cabildo de Tucumán, 1770-1820”, Boletín del Instituto de Historia Argentina y Americana Dr. Emilio Ravignani, No 18: pp. 35-81.

Tío VAllejo, Gabriela (2011): "Los historiadores "hacen justicia": un atajo hacia la sociedad y el poder en la campaña rioplatense en la primera mitad del siglo XIX", Revista de Historia del Derecho, No 41: pp. 199-212.

Valenzuela, Jaime (1990): Bandidaje rural en Chile Central. Curicó, 1850-1900 (Santiago, DIBAM, primera edición).

Zorrilla Concha, Enrique (1942): Esquema de la Justicia colonial (Santiago, Universidad de Chile, publicada bajo el patrocinio y dirección del seminario de Derecho público de la Escuela de Ciencias Jurídicas y Sociales de Santiago, primera edición). 